\title{
Entrevistas con Nuria Espert y Pilar de Yzaguirre ${ }^{1}$
}

\author{
Por María Bastianes \\ (ITEM - Universidad Compluetense de Madrid \\ ARES - Universidad Internacional de La Rioja)
}

\section{Entrevista con Nuria Espert. Actriz ${ }^{2}$}

1. En sus memorias comenta que La Celestina es una obra que, como un fantasma, la persiguió a lo largo de toda su trayectoria como actriz y directora, pero a la que usted no se enfrentó hasta el montaje de Robert Lepage del año 2004. De hecho, le ofrecieron la dirección de una puesta en escena de la obra en el National Theatre de Londres, pero el proyecto finalmente no se llevó a cabo, ¿qué es lo que pasó exactamente? ${ }^{3}$

Pasó que las adaptaciones que me hicieron dos magníficos escritores ingleses no me satisfacían. Me parecía que ambas, o incluso la que al final terminaron trabajando juntos, no eran lo que yo pensaba que era La Celestina. No estaba completo todo lo que de negro tiene ese texto y había personajes muy desarrollados que a mí me parecían secundarios. Me pidieron incluso que les hiciera una escaleta de cómo debían hacer la adaptación, pero finalmente tampoco mi trabajo me satisfizo. Así que, dando un gran paso, decidí hablar con los responsables del teatro (Richard Eyre y David Aukin) para decirles que no haría el proyecto. Me quedé destrozada porque verdaderamente había llegado demasiado lejos antes de echarme atrás, había viajado mucho al National Theatre, habíamos hecho audiciones y ya teníamos el reparto configurado.

1.- El presente trabajo se ha beneficiado de mi vinculación a los proyectos «TEAMAD-CM. Plataforma digital para la investigación y divulgación del teatro contemporáneo en Madrid», financiado por la Comunidad Autónoma de Madrid (código: H2015/HUM-3366), y «PTCE. Primer Teatro Clásico Español. Plataforma para la investigación textual y escénica del Teatro Español del xvI (1496-1542)» del Plan Nacional de Investigación «Excelencia», otorgado por el Ministerio de Economía y Competitividad (código: FF12015-64799-2016-2019).

2.- Esta entrevista telefónica fue realizada el 1 de julio de 2014.

3.- Espert, Nuria, y Ordóñez, Marcos (2002): De aire y fuego, Madrid, Santillana, 298. 
Años más tarde, ya superado todo eso, conseguí hacer realidad un sueño: trabajar con Robert Lepage. Yo le admiraba enormemente y Pilar de Yzaguirre, una buena amiga y una gran mujer de teatro, me facilitó el poder encontrarme con él. Robert propuso montar una versión escénica de La Celestina. Fue difícil y muy costoso porque el montaje era muy caro, Pilar de Yzaguirre se movió mucho, Valencia nos ayudó con el presupuesto y se fue sacando dinero de varias ciudades españolas que coprodujeron el espectáculo. El montaje salió maravillosamente, en mi recuerdo es uno de mis favoritos. Lepage es aún más grande como director de cerca que de lejos, fue un placer único trabajar con él, es una persona asequible, dulce, inteligente, cultísima. Robert trajo consigo una adaptación de Michel Garneau, un poeta canadiense, que era extraordinaria. Garneau había logrado que toda la atmósfera oscura, toda la negrura y el humor estuvieran presentes. Cambiamos el título al de La Celestina, allá cerca de las tenerías, a la orilla del río, que es una frase del libro, para dejar clara la distancia con el original. Fue tan satisfactorio ese trabajo, que ocupa en mi corazón un lugar absolutamente preeminente entre las mejores cosas que yo he hecho nunca; también fue una de las más difíciles de conseguir hacer (hubo que luchar muchísimo), pero, por suerte, salió, y a mi entender, algo brillante.

2. ¿Es posible que también operase un factor histórico en el hecho de que rechazase montar la obra en los ochenta y finalmente aceptase participar en un montaje de La Celestina en 2004? Es decir, ¿qué significaba montar la obra de Rojas a finales de los ochenta y qué significa hacerlo en el siglo XXI?

No creo que el momento histórico influyera en mi decisión en ninguno de los dos casos. Cuando elegí La Celestina para el montaje que me pedía el National Theatre de Londres yo tenía ganas de hacer algo con Joan Plowright, la esposa de Laurence Olivier, con quien ya había trabajado en una versión de La casa de Bernarda Alba que dirigí en Londres. A lo largo de mis setenta años de vida La Celestina ha sido siempre una obra pertinente. Cuando la vi por primera vez (no sé si con Tamayo en 1978 o antes, no recuerdo) era sobrecogedora. Cuando la hicimos con Lepage era escalofriante. Es como el Don Quijote, es completamente intemporal. En este momento de corrupción y tristeza montarla es oportunísimo, pero cuando las cosas nos iban bien era igualmente oportuna.

3. ¿Pudo volcar alguna de las ideas que había pensado para aquel proyecto frustrado del National Theatre en la propuesta de Lepage? 
No, no quise introducir nada de lo poco que yo había avanzado con aquel montaje. Le di completa libertad al director, como hago siempre. A lo largo de mi carrera, por el hecho de tener compañía propia, siempre he sido para mis directores algo más que una actriz, incluso mucho antes de que comenzara yo misma a dirigir. Me convertía en una especie de ayudante de dirección, pero siempre para hacer que las ideas del director llegaran a buen puerto y brillaran. Tanto con Jorge Lavelli, como con Víctor García, Mario Gas, Armando Moreno o Lluís Pasqual. Es un trabajo silencioso, subterráneo, no evidente.

4. ¿Cree que La Celestina ofrece un modelo de clásico más afín con el sentir moderno?

Sí, a mí me parece que es el comienzo de todo. Ella es el canon. Ha dejado una huella de indecencia, de "arriésgate, no releas, sigue», y yo creo que eso está en el teatro que está después de ella.

5. ¿Se tuvieron en cuenta anteriores montajes de la obra o películas para elaborar esta versión?

No, Robert no había visto otros montajes, la había montado él mismo en Estocolmo y no había quedado satisfecho ${ }^{4}$.

6. ¿Se tuvo en cuenta algún tipo de bibliografía sobre la obra de Rojas para preparar el montaje?

No, no recuerdo nada de eso. No fue necesario. Recuerdo que nos fuimos una semana a Salamanca y que estuvimos andando y hablando.

7. En el teatro de Lepage la improvisación y el juego ocupan un lugar central durante el proceso creativo, concebido, además, como un proceso colectivo. ¿Cómo fue el trabajo con los actores en este montaje de La Celestina?

En cuanto empezamos a hacer las audiciones y seleccionó a la gente, nos convertimos de la noche a la mañana en una compañía, en la compañía de Lepage. Él adora al actor y pide colaboración, se trabaja con el texto y se van probando cosas. Cuando te lanzas, propones algo y él lo recibe como si le hicieras unos regalos maravillosos significa que vas por buen camino.

4.- En 1998, seis años antes de la versión española, Robert Lepage había llevado a escena una adaptación de La Celestina de Adam Nashman, que se estrenó el día 8 de agosto en el Dramaten de Estocolmo, como parte de las celebraciones de aquel año en que la ciudad había sido nombrada Ciudad Europea de la Cultura. 


\section{8. ¿Tiene alguna anécdota de los ensayos?}

Recuerdo lo divertido que era Robert, las cosas que contaba, su sentido del humor... Le adorábamos, supongo que le ocurre en todos los lugares donde va. Es tan respetuoso, tan modesto, tan divertido, tan culto. Los ensayos duraron seis o siete semanas y fueron como un taller, todos éramos mejores actores, gente más feliz. Recuerdo el día en que después de una función, al subirnos en el taxi, dijo: «Bueno, Nuria, prepárate que vamos hacer ahora Madre Coraje». Yo casi me desmayo de la alegría. Una vez más una obra que yo no había pensado hacer porque no me atraía me apasionó al instante, en cuanto la eligió. Pero al final pasaron montones de cosas y finalmente no se hizo, ni se hará, me temo

\section{9. ¿Cómo concibe a su personaje?}

Celestina no es una bruja maléfica, es una superviviente. Una mujer que fue una puta barata y cuya única aspiración en la vejez es tener un poco de pan y un poco de vino. Cuando tiene por primera vez en sus manos oro pierde la cabeza. Pero además es una mujer sabia, conoce montones de cosas, es curandera, sabe de ciencias naturales, y es un poco "psicóloga», conoce cómo funciona el interior de las personas.

\section{0. ¿Por qué razón se empleaba un maquillaje tan marcado para Celestina?}

No lo sé, Robert estaba sentado a nuestro lado cuando comenzábamos a buscarlo. En un momento dijo, en broma, que era demasiado guapa para hacer ese papel, que tenía la edad pero que no la aparentaba y que si Celestina hubiese sido como yo le hubiera ido de otra manera en la vida. Así que supongo que quería borrar también mis facciones más reconocibles. Esa transformación prodigiosa que se produce con los maquillajes y el vestuario me resultó muy útil para entrar en el papel, de pronto te miras al espejo y dices "ahí está, es ella, ya ha venido, ya está aquí».

\section{1. ¿Cómo se trabajaron las relaciones entre los personajes?}

Se trabajó muchísimo ese aspecto, hasta el personaje más insignificante tenía un protagonismo que yo no había visto en ninguna versión anterior.

\section{Algunos críticos opinaron que la excesiva maquinaria y el} movimiento de la escenografía interrumpían la acción. ¿Qué se buscaba con el imponente diseño de espacio escénico?

A mí me gusta muchísimo, cuando vas a buscar a Robert Lepage estás pidiendo a gritos un teatro contemporáneo, con todo lo que puede 
brindar técnicamente. Todos sus espectáculos son portentos técnicos y al mismo tiempo historias magníficas

En el caso de los paneles del montaje de La Celestina, allá cerca de las tenerías... creo que Robert no quería un diseño de espacio escénico realista. Los paneles eran como los cuadritos de los retablos medievales a través de los cuales se cuenta una historia. No quería una escenografía llena de telarañas o ratas, sino simplemente generar la sensación de estar contando una historia a través de pequeños pedacitos, de controlar la mirada.

13. Los espectáculos de Lepage no están cerrados a la hora de presentarse al público, continúan construyéndose (ensayándose) en las funciones a partir del contacto con los espectadores. ¿La Celestina allá cerca de las tenerías... experimentó algún cambio a lo largo de sus diversas representaciones?

A lo largo del año de ensayos y actuaciones se realizaron varios cambios: se reestructuró el orden de las escenas, se juntaron dos escenas en una sola, se eliminó una calle, se construyó una pieza necesaria para dar más amplitud a un espacio. Cada vez que aparecía Robert y veía la función teníamos dos o tres días de ensayo y quitaba y ponía; pero era un placer enorme que así lo hiciera: nunca hemos estado todos tan vivos de principio a fin de un espectáculo

14. Con la distancia del tiempo pasado, ¿qué significó para su carrera el montaje? Se suele decir que la alcahueta de Rojas es uno de esos personajes que de alguna manera señala un hito en la carrera de una intérprete, ¿¿lo sintió así en su caso?

No lo sé, es un gran papel y una gran obra, pero con una dificultad: Celestina muere a mitad de la función y los otros personajes, aunque inmensos, no tienen la grandeza y universalidad que tiene la alcahueta. Eso hace que sea un personaje difícil para los directores. Para mí, por ejemplo, fue un escollo insalvable cuando intenté llevar la obra a escena. La actriz tiene que tener una edad respetable, mejor si tiene más de sesenta para que tenga la experiencia necesaria. Decir que una actriz hizo de Celestina sin duda indica qué tipo de actriz es y hasta dónde ha llegado. 


\section{Entrevista con Pilar de Yzaguirre. Directora de Ysarca Art Promotions ${ }^{5}$}

\section{1. ¿Cómo surge la idea de hacer una versión de La Celestina?}

Todo empieza cuando Nuria me llama para decirme que quería trabajar con Robert Lepage. En aquel momento yo llevaba las cosas de Lepage en España y le dije que era difícil porque estaba muy ocupado, pero que lo intentaría. Entre los ofrecimientos que tenían algunos teatros con Nuria y mis influencias con Lepage, pudimos llegar a un acuerdo y finalmente se conocen en Canarias y empiezan a pensar qué harán juntos. Más tarde en Madrid, durante una comida en Lhardy, Robert le propone a Nuria montar La Celestina.

La Celestina, allá cerca de las tenerías a la orilla del río fue una coproducción de Ysarca y Ex Machina. Lepage dudaba entre dos versiones de la obra que le gustaban: la de Adam Nashman, que es la que había utilizado en su montaje de Estocolmo, y la de Michel Garneau. Pedimos, entonces, a Ignacio García May que tradujera el texto de Nashman y a mi marido, Álvaro García Meseguer, que hiciera lo propio con el de Garneau. Finalmente, tanto Robert como Nuria escogieron la versión de mi marido. Álvaro no se dedicaba a la traducción, era lingüista y amaba mucho el lenguaje, todo lo que ha hecho tiene un castellano bellísimo. Recuerdo que durante los ensayos Nuria me dijo: «El castellano de Álvaro es como deslizarse sobre el lenguaje». Además, Carl Fillion, esposo de mi hija, se ocupó de la escenografía. La Celestina pareció entonces como si fuera algo nuestro, de la familia, por la versión de Álvaro y la escenografía de Carl. Hicimos una gira importantísima por España. Una etapa preciosa dentro de Ysarca.

2. ¿Se pensó alguna vez en elaborar una versión a partir del original? ¿Cuánto de propio cree que tuvo la traducción de su marido?

No, trabajamos directamente con la versión de Garneau. El conocimiento del castellano de Álvaro era tan grande que a veces se extendía más allá de la mera traducción. Tengo que decir que mi marido fue felicísimo en esa etapa junto a Robert, que es una persona de gran talento y muy cercana. Lepage iba corrigiendo cosas del texto y la puesta en escena a medida que ensayaba. Tuvo muchos encuentros con Álvaro y los actores, y fueron modificando la versión. Incluso luego del estreno continuó cambiando cosas del espectáculo. El montaje en cada ciudad era distinto. 


\section{3. ¿Cómo fue el trabajo con Lepage y Ex Machina?, ¿hubo al- guna dificultad?}

Fue un encuentro hermoso para Ysarca y para España. Robert se adaptó perfectamente, hizo una versión escénica de La Celestina alegre, viva, sin prejuicios, donde toda la historia sexual se vivía de una forma muy libre, de jolgorio. Se trabaja maravillosamente tanto con Robert como con $\mathrm{Nu}-$ ria. Además, conectaron muy bien entre ellos. Estar con gente de tanto talento y flexibilidad en España no es lo habitual. Sobre todo flexibilidad: no había nada cerrado, a Robert le podías sugerir algo e inmediatamente lo consideraba. Es muy cómodo trabajar con él porque dialoga mucho, no impone nada. De hecho, hay dos actores que participaron en el montaje que luego continuaron trabajando con Lepage: Nuria García (Areúsa), que estuvo luego en Juego de cartas, y Roberto Mori (Pármeno).

Ex Machina trabaja de una forma muy detallista y cuidadosa. Hubo también algunas dificultades y malentendidos fruto del choque entre usos y costumbres de aquí, que no tenían nada que ver con los de allí. Contratar a un actor en España, por ejemplo, no es lo mismo que en Canadá (entre otras cosas, los sueldos son diferentes). En el caso de la puesta en escena de La Celestina, se llevaron a los actores unos meses para que se fueran acostumbrando a Ex Machina, que tiene una manera de trabajar curiosa. Y además hubo algunos problemas con la escenografía: se necesitaban teatros con mucho fondo y en condiciones porque los decorados se movían todo el tiempo. Fue un trabajo duro pero precioso. 


\title{
LA CELESTINA, ALLÁ CERCA DE LAS TENERIAAS, A LA ORILLA DEL RÍO (2004-2006)
}

\author{
AdAptación: Michel Garneau (traducción al español de Álvaro García \\ Meseguer). \\ Dirección: Robert Lepage.
}

COMPAÑía: Ex Machina.

Estreno: 8 de septiembre de 2004, Teatre Lliure (Barcelona).

LUGARES: Barcelona (Teatre Lliure, del 8 de septiembre al 3 de octubre de 2004), Valencia (Nave de Sagunto, del 13 al 23 de octubre de 2004), Madrid (Teatro Español, del 6 de noviembre al 8 de diciembre de 2004), Málaga (Teatro Cervantes, 13 y 14 enero de 2005), Palma de Mallorca (Auditorio de Palma de Mallorca, 21 y 22 de enero de 2005), Pamplona (Auditorio Baluarte, del 4 al 6 de febrero de 2005), Santander (Palacio de Festivales de Cantabria, 4 y 5 de marzo de 2005), Bilbao (Teatro Arriaga de Bilbao, del 12 al 20 de marzo de 2005), Gijón (Teatro Jovellanos, del 1 al 3 de abril de 2005), Salamanca (Centro de las Artes Escénicas, del 8 al 10 de abril de 2005), Las Palmas de Gran Canaria (Teatro Cuyás, del 22 al 24 de abril de 2005), Tenerife (Teatro Guimerá, del 1 al 3 de mayo de 2005), Sevilla (Teatro La Maestranza, 28 y 29 de junio de 2005), Milán (Piccolo Teatro di Milano, del 2 al 5 de febrero de 2006).

Reparto: Nuria Espert (Celestina), Carmen del Valle (Melibea), David Selvas (Calisto), Pep Molina (Sempronio, Tristán), Roberto Mori (Pármeno, Sosia), Nuria Moreno (Elicia), Nuria García (Areúsa), Marta Fernández Muro (Lucrecia), Miguel Palenzuela (Pleberio), Carmen Arévalo (Alisa), Alejandro Sigüenza / Miguel Puchades (Centurio, Crito y Cristo).

RESTO DEL EQUiPO: Sophie Martin (asistente dirección de escena), Carl Fillion (escenografía), Silvy Grenier (compositora de la música e intérprete), François Barbeau (diseño de vestuario), Etienne Boucher (diseño de luces), Jean-Sébastien Coté (diseño de sonido), Sylvie Courbron (diseño de utilería), Montserrat Tolosa (maquillaje), Carlos Montosa (pelucas), Serge Coté (director técnico), Pilar García de Yzaguirre (directora de producción en gira), Eduardo Moreno (director técnico en gira), Francisca Pantoja (jefa de maquinaria), Juan Manuel Pérez Fernández / Javier Iglesias / Gema Portolés / Blanca Sancho / Ana Iglesias (maquinistas), Oscar Rodríguez (jefe de rigging), Nicolas Domicile (jefe de iluminación), Jaime García de Vinuesa (ingeniero de sonido), Maite Prieto (regidora), Mathilde 
López (asistente de escenografía), Oscar Botinas (asistente de producción en gira), Yves Gagnon (asesor de acrobacias), Scène Éthique (construcción de escenografía), Elisa Echegaray (asistente de vestuario en España), Miguel Ángel Castro (asesor telar), Curiosa S.L. (taller de construcción de telares), Transdecor (transportes en gira), Lynda Beaulieu (agente del director de escena), Pilar García de Yzaguirre (adjunta de producción), Elisa Ibarrola de Andrés (administración), Pilar García de Yzaguirre (productora ejecutiva de Ysarca), Michel Bernatchez (productor ejecutivo de Ex Machina).

Fuente: Memoria de actividades de "Ysarca. Art Promotions", Pilar de Yzaguirre (dir.), [en línea] en <http://www.ysarca.com/ysarca.html> [consultado el 17/01/2017]. 
